\title{
FREQUENCY OF OSTEOPOROSIS IN IATROGENIC CUSHING'S SYNDROME: SCENARIO OF OUTPATIENT DEPARTMENT IN URBAN HOSPITALS
}

\author{
TAMANNA BAHAR ${ }^{1}$, SHAILA RAHMAN ${ }^{2}$, LILIAN CATHERENE GOMES ${ }^{3}$, MOHAMMAD MURAD HOSSAIN ${ }^{4}$, \\ ZULFIA ZINAT CHOWDHURY ${ }^{5}$, ANWAR HOSSAIN ${ }^{6}$
}

\begin{abstract}
Background: Cushing's syndrome is caused by excessive activation of glucocorticoid receptor. Iatrogenic Cushing syndrome is the prevalent one world -wide .Patients with Cushing's syndrome has a high prevalence of osteoporosis.

Objective: To see the prevalence of osteoporosis in Iatrogenic Cushing's syndrome patient.

Method: This descriptive cross-sectional study included 211 diagnosed case of Cushing's syndrome during the time period of December 2013 to December 2018 in outpatient department of Dhaka Medical College and Health and Hope Hospital. Final diagnosis was done on the basis of clinical feature, serum basal cortical level and BMD. We found male were prevalent one (56\%). $80.56 \%$ showed biochemical evidence of Cushing's syndrome. BMD was done in 113 patients compared with a reference population by means of $T$ score, $17.69 \%$ patient in osteoporotic range.

Conclusion: The prevalence of osteoporosis and osteopenia is age and sex independent. Judicial use of steroid and co administration with calcium, bisphosphonate can prevent osteoporosis. Treatment with bisphosphonates should be considered in all patients (irrespective of age) with Cushing's syndrome with a low BMD to reduce fracture.
\end{abstract}

Key words: Iatrogenic Cushing's syndrome, Osteoporosis, Osteopenia, BMD.

Received: 20 June 2019

Accepted: 18 December 2019

DOI: https://doi.org/10.3329/bjmed.v31i1.44857

\section{Introduction:}

Iatrogenic Cushing's syndrome is usually related to prolonged and/or high -dose steroid in various formulations. The association between hypercortisolism and loss of skeletal mass was first described by Harvey Cushing ${ }^{1}$.Cushing's syndrome has multiple effects on bone metabolisim. Elevated cortisol level directly inhibit bone formation and indirectly influence the skeleton via effects on reproductive hormones, muscle, fat tissue, intestinal calcium absorption and renal calcium excretion ${ }^{2,3}$. As a result patients frequently show lower measurement of bone mineral density (assessed by dual-energy X-ray absorptiometry [DXA], abnormalities in bone micro architecture, lower estimates of bone strength and an increased risk of fracture compared to healthy individuals. Fractures often occur with minimal or no antecedent injury and can occur in patients with normal measurements of bone mineral density ${ }^{4}$. The currently accepted definition of osteoporosis is "a systemic disease characterized by low bone mass and microarchitectural deterioration of bone tissue leading to enhanced bone fragility, and consequent increase in fracture risk". The tests that forms the basis for the diagnosis of osteoporosis and prediction of fracture risk are bone mineral density (BMD) and bone mineral content (BMC) measurements ${ }^{5,6}$ The study was intended to find out the prevalence of osteoporosis in Iatrogenic Cushing's syndrome.

1. Assistant registrar, Department of Hematology, National Institute of Cancer Research and Hospital

2. Assistant Professor, Department of Medicine, Shahbuddin Medical College and Hospital

3. Medical Officer, Department of Physical Medicine \& Rehabilitation, BSMMU, Shahbag, Dhaka

4. Associate Professor, Department of Medicine, Dhaka Medical College

5. Medical Officer, Department of Hematology, National Institute of Cancer Research and Hospital

6. Registrar, Department of Medical Oncology, National Institute of Cancer Research and Hospital

Address of Correspondence: Dr. Tamanna Bahar, Assistant Registrar, Department of Hematology, National Institute of Cancer Research and Hospital, E-mail: tamanna.bahar@yahoo.com

Bangladesh J Medicine 2020; $31: 18-21$ 


\section{Methods:}

This observational cross sectional study was carried out in outpatient department of Dhaka Medical College and Hospital and Health and Hope Hospital, during the period of December 2013 to December 2018.Total 211 patients were selected after diagnosis of iatrogenic Cushing's syndrome .Data was processed and analyzed by SPSS version 24 .

\section{Result:}

Total 211 patients was analyzed $.27 .48 \%$ patients were in the age group 50-59 years.

\section{Table-I}

Age distribution of patients taking corticosteroid $(n=211)$

\begin{tabular}{lcc}
\hline Age in years & Frequency & Percentage \\
\hline$<20$ & 4 & 1.89 \\
$20-29$ & 21 & 9.95 \\
$30-39$ & 50 & 23.69 \\
$40-49$ & 54 & 25.59 \\
$50-59$ & 58 & 27.48 \\
$60-69$ & 16 & 7.5 \\
$70-79$ & 8 & 3.79 \\
\hline
\end{tabular}

Men (56\%) were slightly higher than female (44\%).

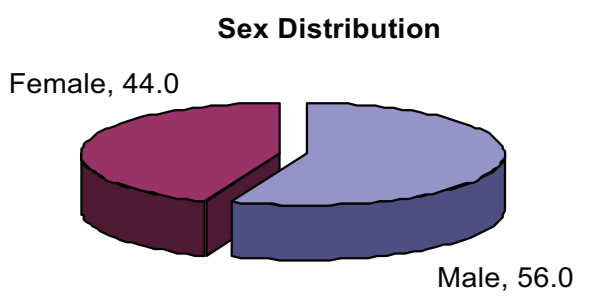

Fig.-1: Sex distribution of study population ( $n=211)$

Most of them $71.56 \%$ came from rural area and $28.43 \%$ were urban dweller.

Table-II

Distribution according to dwelling ( $n=211)$

\begin{tabular}{lcc}
\hline Habitant of the patient & Frequency & Percentage \\
\hline Rural & 151 & 71.56 \\
Urban & 60 & 28.43 \\
\hline
\end{tabular}

Most of the patient took corticosteroid in oral route $86 \%, 12 \%$ parenteral route and $2 \%$ in topical route.

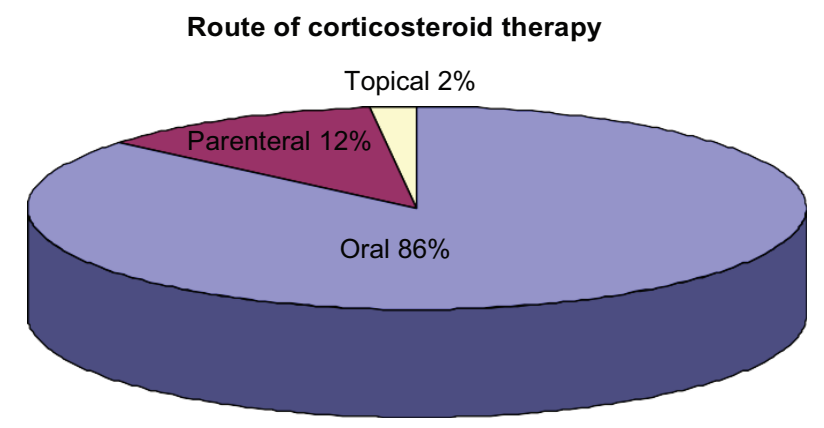

Fig.-2: Route of administration of corticosteroid therapy $(n=211)$

Prednisolone was taken by most of the patient $(77.72 \%)$, than dexamethasone $(18 \%)$, triamcinolone $(2.84 \%)$, betamethasone $(1.42 \%)$. Most of the patient took steroid equivalent to11-20 mg of prednisolone $(34.12 \%)$ and duration up to 6 month was more prevalent (42.1\%)

\section{Table-III}

Pharmacological preparation of corticosteroids with doses and duration of treatment $(n=211)$

\begin{tabular}{lcc}
\hline Pharmacological name & Frequency & Percentage \\
\hline Prednisolone & 164 & 77.72 \\
Dexamethasone & 38 & 18 \\
Triamcinolone & 6 & 2.84 \\
Betamethasone & & 1.42 \\
Doses of steroid(equivalent of prednisolone) & \\
$<7.5$ mg & 13 & 6.16 \\
$7.6-10$ mg & 55 & 26.06 \\
$11-20$ mg & 72 & 34.12 \\
$>20$ mg & 21 & 10 \\
Undetermined & 50 & 23.69 \\
Duration of cortisteroid therapy & \\
Upto 6 month & 89 & 42.1 \\
$7-12$ month & 46 & 21.8 \\
13-24 month & 42 & 19.9 \\
25-36 month & 21 & 10 \\
37 \& above & 13 & 6.16 \\
\hline
\end{tabular}

Basal serum cortisol was done in every patient, $80.56 \%$ patient biochemical feature of Cushing's syndrome. 
Table-IV

Basal serum cortisol $(n=211)$

\begin{tabular}{lcc}
\hline $\begin{array}{l}\text { Dexamethasone } \\
\text { suppression test }\end{array}$ & Frequency Percentage \\
\hline Plasma cortisol level>60 nmol/1 & 170 & 80.56 \\
Plasma cortisol<60 nmol/1 & 41 & 19.44 \\
\hline
\end{tabular}

Among 211 patients BMD was done in 113 patients. Most of them were in mild to moderate osteopenic range (42\%), 39\% were in normal range and $17.69 \%$ patient were in osteoporotic range.

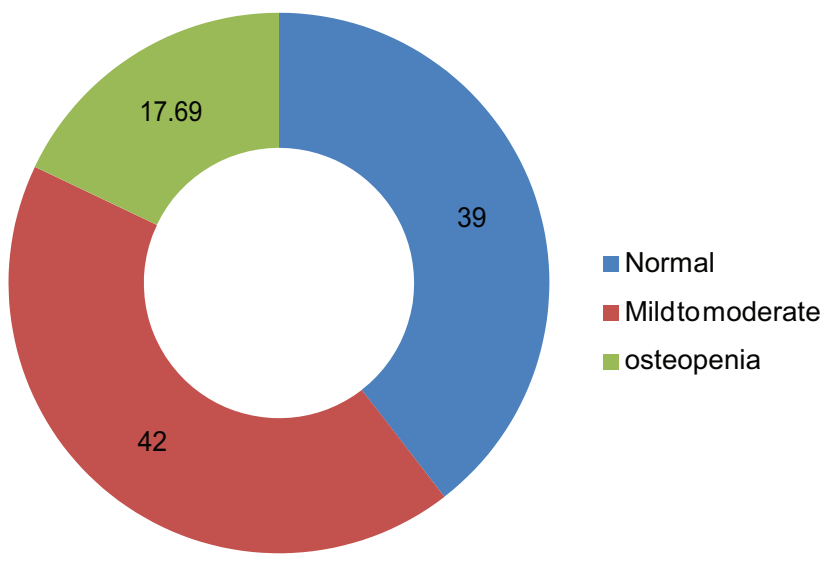

Fig.-3: $B M D$ in patients taking corticosteroids ( $n=113)$

\section{Discussion:}

In this study we found $27.48 \%$ were in the age group of 50-59 years, the youngest patient was 14 years of age and the eldest one was 79 years of age, which was similar to the findings of that of netherland ${ }^{4}$ and india 8 , where most of them were more than 40 years of age. Overall sex distribution, male were more prevalent one, which was significantly difference from that of India , where female were more prevalent one ${ }^{8}$.Female are more reluctant to seek medical services due to shyness, religious belief, economic dependency on male.

A variety of pharmacological preparation was used among them most common was oral prescribed steroid $(86 \%)$, even topical used steroid found in $2 \%$ cases which was rare in western countries ${ }^{4}$ but similar to Asian ethnicity ${ }^{8}$. Prednisolone was used in most of the cases $77.72 \%$, less common is Betamethasone (1.42\%) which was slightly differ from other studies ${ }^{4,6,8}$. The majority of dose range was 11-20 mg (equivalent to prednisolone) $34.12 \%$, in $23.69 \%$ cases dose ranges was not found may be due to patients reluctant to steroid intake, lack of proper counseling, lack of proper knowledge of steroid side effect. Among 211 patients we found that $42.1 \%$ patient took steroid up to 6 month and $6.16 \%$ took more than 37 month may be due to rapid relief of symptoms, easy availability.

For confirmation of diagnosis all patients were taken for Basal serum cortisol level at 9 am and revealed that $80.56 \%$ were in range group lower than the normal and $19.44 \%$ were in lower level of normal range. As iatrogenic Cushing's syndrome is mainly a clinical diagnosis, normal level does not exclude the disease.

To establish the diagnosis of osteoporosis we did BMD in 113 patients and found 39\% were in normal range, $42 \%$ in mild to moderate osteopenc and $17.69 \%$ in osteoporotic range much higher than other studies. ${ }^{4,8}$

The paucity of laboratory investigation facilities in Bangladesh, especially in the area other than Dhaka city, the diagnosis of Cushing's syndrome was a difficult one. We mainly emphasized on the clinical feature and duration of drug used. Judicial use of steroid , legislation of prescribed steroid can prevent osteoporosis in people.

\section{Conclusion:}

The prevalence of Iatrogenic Cushing's syndrome in Bangladesh is not identified. The present study was conducted in outpatient department of various hospitals in Dhaka city with a limited Data. Among 211 patients most them were young adult, male were more prevalent. Most of them took steroid in oral form. A great number of patients had osteopenic range which can be prevented by judicial use of steroid, proper counseling, co administration with bisphosphonate, restriction of steroid availability without prescription, patients' education about side effect of steroid.

\section{Limitation:}

This is a cross sectional study with limited data. Randomized controlled trail was not done to see the frequency of osteoporosis.

\section{References:}

1. Cushing H. The basophil adenomas of the pituitary body and their clinical manifestations. Bull Johns Hopkins Hosp 1932;1:137-95.

2. Godang K, Ueland T, Bollerslev J. Decreased bone area, bone mineral content, formative markers, and increased bone resorptive markers in endogenous Cushing's syndrome. Eur J Endocrinol 1999;141:126- 31.https:/ /doi.org/10.1530/eje.0.1410126.PMid:10427155

3. Weinstein RS, Jilka RL, Parfitt AM, Manolagas SC. Inhibition of osteoblastogenesis and promotion of apoptosis of osteoblasts and osteocytes by glucocorticoids. Potential mechanisms of their 
deleterious effects on bone. J Clin Invest 1998;102:27482. https://doi.org/10.1172/JCI2799.PMid:9664068 PMCid:PMC508885

4. A.W. van der Eerden1, M. den Heijer1,2*, W.J Oyen3, A.R Hermus;Cushing's syndrome and bone mineral density: lowest $Z$ scores in young; the journal of medicine(netherland) a p ri 12007 , V o 1.65 (4):137141.

5. Rafal S. Filip, Jerzy Zagorski. Bone mineral density and osteoporosis in rural and urban women.Epidemiological study of the Lublin region (Eastern Poland). Ann Agric Environ Med 2001; 8:221- 226.

6. Fogelman I, Blaek GM. Different approaches to bone densitometry. J Nucl Med 2000; 41(12):2015- 2025.
7. Begum S M F,Begum R,Alam R.Bone Mineral Density and Osteoporosis in Women of Rural and Urban Dwellers.Bangladesh J. Nucl. Med. 2015;18(1):39-42. https://doi.org/10.3329/bjnm.v18i1.34932

8. Nandyala V, Prasad TK, GandiahP. Iatrogenic cushing's syndrome in admitted patients to a rural based medical college hospital. International Journal of Contemporary Medical Research 2017;4(1):17-21

9. Fardet L, Petersen I, Nazareth I. Prevalence of longterm oral glucocorticoid prescriptions in the UK over the past 20 years. Rheumatology (Oxford). 2011;50:1982-90. https://doi.org/10.1093/ rheumatology/ker017.PMid:21393338 